\title{
Psychosocial outcomes of children and parents after renal transplantation
}

\author{
P R D Ranawaka ${ }^{1}$, C K Abeysekera ${ }^{2}$, M P Gamage ${ }^{3}$, O R Illangasekara ${ }^{4}$, G R C Silva ${ }^{5}$, D S G \\ Mettananda $^{6}$, T Pathmanathan ${ }^{2}$, A S Abeyagunawardena ${ }^{2}$
}

Sri Lanka Journal of Child Health, 2015; 44(1): 38-44

\begin{abstract}
Introduction: Although some highlighted problems such as parental stress, child behavioural problems and financial instability occur after transplantation, much still remains unknown about the extent, nature, reasons and implications of family difficulties caused by renal transplantation in childhood.
\end{abstract}

Objectives: To examine the psychosocial aspects, levels of parental stress and behavioural problems among children after renal transplantation and to study the predictors of psychosocial issues in the study sample.

Design, setting and method: A cross sectional analytical study was conducted at the University Paediatric Unit of the Teaching Hospital, Peradeniya in September-October 2012. All patients who are being followed up at the post renal transplant clinic were recruited to the study. Data was collected using an intervieweradministered questionnaire and analyzed using SPSS 16.0.

Results: Thirty-eight recipients of paediatric renal transplants were recruited. $67.5 \%$ were males. Feeling of happiness constantly or regularly was reported by $82.5 \%$ of children while irritability was a significant problem in $47.5 \%$. Sleep disturbance was a recognized problem in $50 \%$ of children. At 2 years of transplantation $85 \%$ of children had not attended school but at 5 years after transplantation school dropout was $10 \%$. This difference was

${ }^{1}$ Senior Registrar, Paediatric Nephrology, Department of Paediatrics, Faculty of Medicine, University of Colombo, ${ }^{2}$ Professor in Paediatrics, University Paediatric Unit, Teaching Hospital, Peradeniya, ${ }^{3}$ Medical Officer, Base Hospital, Elpitiya, ${ }^{4}$ Medical Officer, Base Hospital, Gampola, ${ }^{5}$ Senior Registrar, Obstetrics and Gynaecology, Teaching Hospital, Peradeniya, ${ }^{6}$ Senior Registrar, Paediatrics, University Paediatric Unit, Teaching Hospital, Ragama

(Received on 20 May 2014: Accepted after revision on 20 June 2014) statistically significant $\left[\mathrm{X}^{2}=25.8, \mathrm{p}<0.001\right]$. $52.5 \%$ of parents had expressed their stress on a constant or regular basis. $37.5 \%$ of fathers had lost their jobs consequent to renal transplantation and $30 \%$ of families had a monthly income less than LKR 10, 000.

Conclusions: $82.5 \%$ of children reported feelings of happiness on a constant or regular basis after renal transplantation. Non-attendance at school was observed in $85 \%$ at 2 years of transplantation but the school dropout was $10 \%$ at 5 years after transplantation. $52.5 \%$ of parents had expressed their stress on a constant or regular basis.

(Key words: Renal Transplantation; psychosocial outcomes; children; parents)

\section{Introduction}

Some problems that occur after renal transplantation have been highlighted, including symptoms of depression, poor self-esteem, noncompliance with treatment, family disruptions and poor growth ${ }^{1}$. A recent long-term outcome study indicated considerable psychological problems, with a quarter of subjects having seen a doctor for a persistent emotional or psychiatric problem in early adulthood ${ }^{2}$. Further, a recent study suggests that rehabilitation after transplantation should include a focus on physical activity and quality of life to reduce interconnected physical and psychological morbidity in kidney transplant children ${ }^{3}$.

The study of the effects of chronic childhood illness on marriage shows that although stress on the marriage is often apparent, when control design is used, there is no evidence of a rise in divorce rates of couples with chronically ill children $^{4}$. Many previous studies have noted family disruption in children with end stage chronic renal failure, on haemodialysis, or after transplantation ${ }^{5-7}$.

Earlier studies have stated good long term quality of life (QOL) and psychosocial outcome after kidney transplantation during childhood ${ }^{8-10}$ : however, most of these studies were conducted with adult patients. Studies on mental health and 
psychosocial functioning are even scarcer and are divergent in their findings. Some indicate no differences between transplant recipient and the healthy control ${ }^{11-13}$, whereas others report an increased risk of maladaptive psychosocial sequels with emotional disturbances, such as anxiety, fear, depression, anger, withdrawal and symptoms of posttraumatic stress ${ }^{14}$. Further, a recent study on 'changes in psychosocial adjustment after renal transplantation' revealed that kidney transplantation is associated with improved psychosocial behaviour in children, but there is a continuing need of support for parents in dealing with minor psychological problems after the transplant ${ }^{15}$. Most of these studies were done in developed countries and there is a dearth of studies from developing countries including Sri Lanka.

\section{Objectives}

- $\quad$ To examine the psychosocial aspects, levels of parenting stress and child behaviour problems in a sample of children after renal transplantation.

- To study the predictors of psychosocial issues in the study sample.

\section{Method}

This cross-sectional analytical study was conducted in the Paediatric Kidney Transplant Clinic in the Teaching Hospital Peradeniya during September-October 2012 after obtaining permission from the head of the institution. Ethical clearance was obtained from the Ethical Review Committee, Faculty of Medicine, University of Peradeniya. Teaching Hospital Peradeniya is the only Paediatric Kidney Transplant Centre in Sri Lanka at present. A Consultant Paediatrician conducts the Paediatric Kidney Transplant Clinic weekly and care is provided for about 40 post transplant patients aged below 18 years.

During the month of July 2012, all the patients who were being followed up at the clinic were recruited to the study. Parents/caretakers were informed about the study and written consent was obtained before recruiting their children into the study. Following recruitment the principal investigator interviewed the parent or caretaker and went through the child's clinical records to gather relevant information for the study (e.g. Date of transplant, Donor detail etc). Data was collected using a pretested interviewer administered questionnaire. Questionnaire was made after consultation with experts in the
Department of Psychiatry, University of Peradeniya. The Paediatric Quality of Life Inventory (PedsQL) version $4.0^{16,17}$ was used as a reference. Some modifications to the questionnaire were made after focus group discussion. Questionnaire contained questions on age, sex \& height of children, duration of the transplant, financial status of the family and questions to assess psychosocial issues in children and parents/caretakers. Validity of the instrument was assessed by performing a factorial analysis and reliability was assessed by performing Cronbach's alfa test using SPSS 16.0. Data was entered into worksheet in Microsoft Excel and analysed using computer package SPSS 16.0 for windows. Chi square test, Student $\mathrm{T}$ test and multiple logistic regression was used in the analysis. An Assessment Scale was introduced to analyse questions no 8-12 and 14-20 as follows:

- Constant: Occurs on a daily basis

- Regular: Occurs on less than daily basis but more than once a week

- Occasionally: Occurs once or less than once a week but more than once a month

- Rarely: Occurs once or less than once a month

- Never: No occurrence

Question no 13 was analysed as follows: Satisfactory- school absences less than 5 days per month and five or more absences taken as non-satisfactory.

This was a self-funded study.

\section{Results}

The sample included 40 recipients of paediatric renal transplants. Approximately two third $(67.5 \%)$ were males. The donor relationship is shown in Table 1.

Table 1: Donor relationship

\begin{tabular}{|l|c|}
\hline Donor Relationship & Frequency (\%) \\
\hline Father & $11(27.5)$ \\
\hline Mother & $15(37.5)$ \\
\hline Priest & $08(20.0)$ \\
\hline 2nd degree relative & $04(10.0)$ \\
\hline Grand father & $02(05.0)$ \\
\hline Total & $40(100)$ \\
\hline
\end{tabular}

The donor was either the mother or father in $65 \%$ cases. Interestingly, there were eight priests within the donor cohort. Transplant duration was less than 2 years in $16(40 \%), 2-5$ years in 14 $(35 \%)$ and more than 5 years in $10(25 \%)$. The longest transplant duration was 8 years and age 
of the smallest child to have undergone renal transplantation was one year and nine months with $8 \mathrm{~kg}$ weight. At least one episode of rejection was seen in $42.5 \%$. Parents were asked to rate the degree and direction of change in the child's and parents' psychosocial wellbeing and behaviour and in the quality of family life since transplantation. Assessment of the child's emotional and behaviour status is shown in Table 2.

Table 2: Assessment of child's emotional and behaviour status

\begin{tabular}{|l|c|c|c|c|c|}
\hline \multicolumn{1}{|c|}{ Status } & $\begin{array}{c}\text { Constantly } \\
\text { No. }(\%)\end{array}$ & $\begin{array}{c}\text { Regularly } \\
\text { No. }(\%)\end{array}$ & $\begin{array}{c}\text { Occasionally } \\
\text { No. (\%) }\end{array}$ & $\begin{array}{c}\text { Rarely } \\
\text { No. (\%) }\end{array}$ & $\begin{array}{c}\text { Never } \\
\text { No. (\%) }\end{array}$ \\
\hline Happiness & $17(42.5)$ & $16(40.0)$ & $07(17.5)$ & $0(0.0)$ & $0(0.0)$ \\
\hline Irritability & $06(15.0)$ & $13(32.5)$ & $16(40.0)$ & $05(12.5)$ & $0(0.0)$ \\
\hline Peer group socialization & $03(07.5)$ & $24(60.0)$ & $09(22.5)$ & $03(07.5)$ & $0(0.0)$ \\
\hline $\begin{array}{l}\text { Participation in extracurricular } \\
\text { activities }\end{array}$ & $01(02.5)$ & $16(40.0)$ & $07(17.5)$ & $13(32.5)$ & $03(07.5)$ \\
\hline Sleep disturbances & $0(0.0)$ & $04(10.0)$ & $16(40.0)$ & $01(02.5)$ & $19(47.5)$ \\
\hline
\end{tabular}

Feeling of happiness constantly or regularly was reported by $82.5 \%$ of children while irritability was a constant or regular problem in $47.5 \%$. Moreover, about $50 \%$ of children complained of sleep disturbances. (Table 2). Many children continue to have school disturbances even after renal transplantation. It is exemplified by the fact that at 2 years of transplantation $85 \%$ of children had not attended school but at 5 years after transplantation school dropout was $10 \%$. This difference was statistically significant $\left[\mathrm{X}^{2}=25.8\right.$, $\mathrm{p}<0.001]$. Even though $90 \%$ of children were attending school at 5 years after renal transplantation, only $60 \%$ of them had shown satisfactory school attendance. The assessment of parental problems is shown in Table 3.

Table 3: Assessment of parental problems

\begin{tabular}{|l|c|c|c|c|c|}
\hline \multicolumn{1}{|c|}{ Problem } & $\begin{array}{c}\text { Constantly } \\
\text { No. (\%) }\end{array}$ & $\begin{array}{c}\text { Regularly } \\
\text { No. }(\%)\end{array}$ & $\begin{array}{c}\text { Occasionally } \\
\text { No. (\%) }\end{array}$ & $\begin{array}{c}\text { Rarely } \\
\text { No. (\%) }\end{array}$ & $\begin{array}{c}\text { Never } \\
\text { No. (\%) }\end{array}$ \\
\hline Stress & $06(15.0)$ & $15(37.5)$ & $16(40.0)$ & $03(07.5)$ & 0 \\
\hline Hopelessness & $0(0.0)$ & $19(47.5)$ & $17(42.5)$ & $03(07.5)$ & 1 \\
\hline Marital disharmony & $0(0.0)$ & $07(17.5)$ & $04(10.0)$ & $04(10.0)$ & 25 \\
\hline Neglect of home duties & $0(0.0)$ & $12(30.0)$ & $12(30.0)$ & $14(35.0)$ & 2 \\
\hline Social embarrassment & $0(0.0)$ & $02(05.0)$ & $19(47.5)$ & $03(07.5)$ & 16 \\
\hline Neglect of sibling wellbeing & $0(0.0)$ & $09(22.5)$ & $12(30.0)$ & $07(17.5$ & 4 \\
\hline Missing social activities & $09(22.5)$ & $17(42.5)$ & $10(25.0)$ & $04(10.0)$ & 0 \\
\hline
\end{tabular}

A significant number $(52.5 \%)$ of parents had expressed their stress on a constant or regular basis and $47.5 \%$ had constant hopelessness even after the renal transplantation. In contrast, there were no marital disharmonies in $62.5 \%$ of families. A high percentage $(65 \%)$ of parents missed their social activities constantly or regularly (Table-3). Education levels of mothers were satisfactory. $55 \%$ of mothers were educated up to AL/OL compared to $35 \%$ of fathers. Assessment of socio-economic status is shown in Table 4.

Table 4: Assessment of socio-economic status

\begin{tabular}{|l|c|c|}
\hline \multicolumn{1}{|c|}{ Status } & $\begin{array}{c}\text { Yes } \\
\text { Frequency (\%) }\end{array}$ & $\begin{array}{c}\text { No } \\
\text { Frequency (\%) }\end{array}$ \\
\hline Father lost job & $15(37.5)$ & $25(62.5)$ \\
\hline Mother lost job & $02(05.0)$ & $38(95.0)$ \\
\hline Parents gone abroad & $06(15.0)$ & $34(95.0)$ \\
\hline Debts & $27(67.5)$ & $13(32.5)$ \\
\hline Financial assistance & $11(27.5)$ & $29(72.5)$ \\
\hline Family support & $17(42.5)$ & $23(57.5)$ \\
\hline
\end{tabular}


Financial problems of these families are alarming. More than one third (37.5\%) of fathers had lost their jobs consequent to renal transplantation and $30 \%$ of families had a monthly income less than LKR 10, 000. The monthly income is shown in Figure 1.

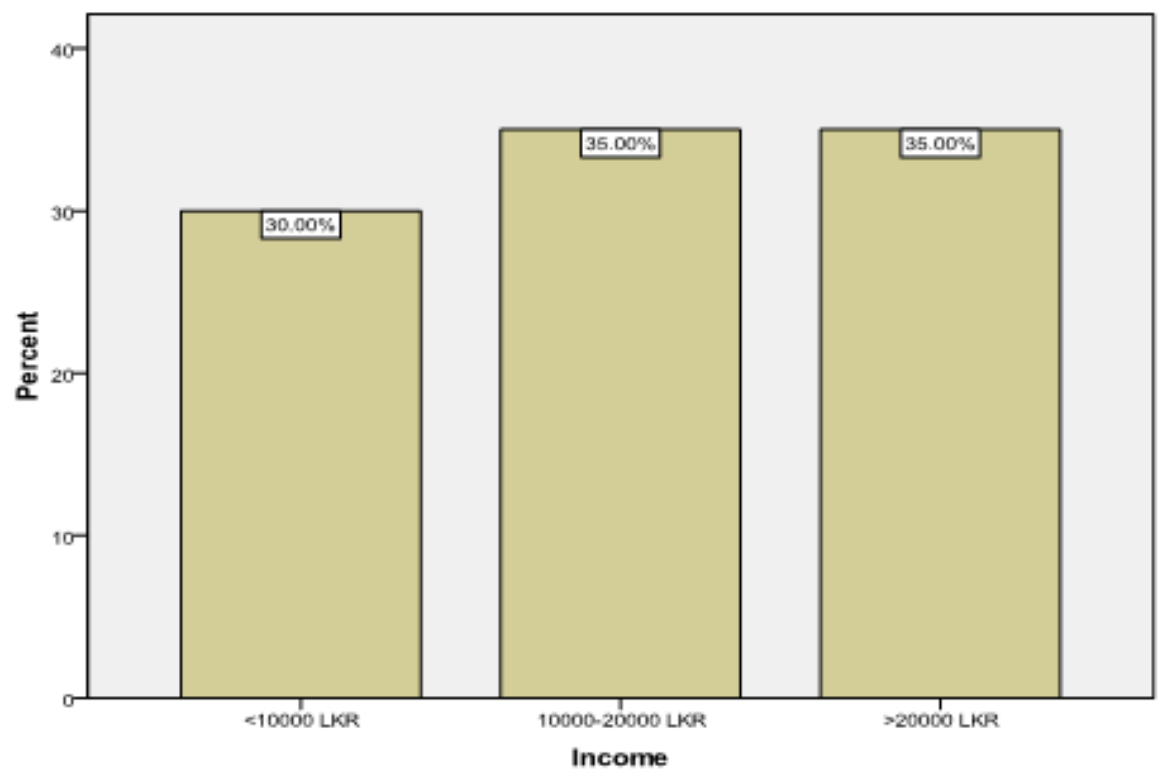

Figure 1: Monthly income

\section{Discussion}

The results of our study demonstrate that both children and their parents carry a significant burden that last up to several years after renal transplantation and therefore reflect the documented psychological and social at-risk status for children with chronic health conditions reported in the literature ${ }^{18,19}$. Even though some studies found significant association with the duration of transplant and the emotional and behavioural patterns, our study did not find such an association ${ }^{2,5,20}$.

The psycho-behavioral disturbances in children such as irritability and sleep disturbances were still a major problem in our transplant children, reflecting long term psychological stress and their difficulties in making the transition from being ill to being healthy. The same observation was seen in previous studies reporting different rates and types of psychological morbidity after transplantation ${ }^{20,21}$.

On the other hand, our finding show that improved physical health of children after transplantation is paralleled by pronounced improvement in their parents' perception of the children's emotional status as suggested by increased feeling of happiness in children after transplantation. Similar observations have been made by Reynold J et al. ${ }^{15}$.

In contrast to other studies ${ }^{8,22,23}$, it is noteworthy that our transplant children had a major problem with school attendance. As most of them have presented in late stages of CKD, even before the transplantation they have not had proper school attendance. Fear of infections, difficulty in transition from ill health to healthy status, concerns of body appearance, need to wear mask and parental anxiety were some of the reasons for nonattendance to school after transplantation.

Furthermore, much has been made in previous reports of concerns by children about their appearance $^{2,5}$. Issues such as short stature, hirsutism, and body image emerge quite regularly as areas of concern, and it may be that interviews with the children themselves would have been necessary to assess fully the degree of these concerns.

Our results suggested that even after the renal transplantation, more than half the parents $(52.5 \%)$ are inflicted with continuous stress. Parents had concerns about their children's health which encompassed both medical prognosis of the graft and developmental issues, such as growth. Moreover, parents are worried 
regarding children's education and future events such as marriage.

However, many studies had shown contrasting findings to our results indicating less stress and anxiety following renal transplantation ${ }^{15,20,21}$. This should be viewed against the back ground of different degree of psycho-social support available in different institutions.

Many previous studies reported perception of far less disruption to life styles after renal transplantation with more freedom, more energy, and time for normal family activities such as going away on holidays ${ }^{15,24}$. This contradicts our findings which reported about two third of parents missed social activities even after renal transplantation. Fear of contacting infections and myths on participating in social events like funerals were some of the causes.

However, at the time of assessment nearly seventy percent of parents whose children had received transplant reported no marital disharmony. Our findings on the effects of the transplantation specifically highlight the fact that although illness often has an impact in this area, it can operate in the direction of increased support. This would explain the lack of significant increase in marital breakdown in the families of ill children, which is in keeping with Sabbeth and Leventhal's conclusion from their literature review ${ }^{4}$.

At the time of assessment more than one third of fathers had lost their jobs consequent to renal transplantation of which $60 \%$ were donors. We noted that some of the fathers commented on standing the demand of work hard to cope with, particularly at times of problems in the child's illness. Other authors have reported work problems in fathers or feelings of resentment when work prevented them from being concerned with treatment and with the child at the hospital ${ }^{6,25}$.

Furthermore, our results suggested that nearly one third of families had monthly income of less than 10,000 LKR. Undoubtedly, this financial stress would affect their quality of life considering the extra expenses they have to bear to look after a child with renal transplantation. Even though, such economic issues are a rarity elsewhere, in our setup it is a major issue. Thus, it is worth considering a special scheme of financial support for these families and job security for donor fathers.

\section{Conclusions}

- $82.5 \%$ of children reported feelings of happiness constant or regular basis after renal transplantation.

- Non-attendance at school was observed in $85 \%$ at 2 years of transplantation but the school dropout was $10 \%$ at 5 years after transplantation.

- $\quad 52.5 \%$ of parents had expressed their stress on a constant or regular basis.

Finally, mental health problems and psychosocial dysfunction can persist several years after treatment with renal transplantation, affecting the transplant child's quality of life and parental functioning. The support should not just encompass physical issues but also psychological and social ones. A paediatric team that is aware of psychosocial issues will be able to meet many of the needs of transplant patients and their families, but should be able to make specific referrals where appropriate. Thus, optimal treatment and follow up of transplant children require close collaboration between paediatricians and psychosocial experts and their professional guidance should be offered routinely to the transplant patients and their parents.

\section{Limitations}

1. One parent was interviewed and he/she was the main care giver. As most of the patients are from faraway places it was difficult to arrange interview from both parents without disturbing their routine life styles. A lack of concordance between children and caregivers has been reported, suggesting information provided by proxy respondents is not equivalent to that reported by the patient. The child perspective often diverges from parental perceptions, particularly in the emotional and social domains. Previous research in CKD children and their parents has emphasized that the caregivers perception of their child may underestimate the patient's own perception ${ }^{25}$. On the other hand mothers with more psychological problems often rate their children as having more behavioral problems.

2. Our study was based on interviewer administered questionnaire. These general nonspecific questionnaires underestimate the overall prevalence of psychosocial 
dysfunctioning and psychopathology. More specific psychosocial problems and mild psychopathology appear to be difficult to elicit by questionnaires indicating the need for including semi structured psychiatric or qualitative interviews within disease specific areas.

\section{References}

1. Bernstein DM. After transplantation - the child's emotional reactions. American Journal of Psychiatry 1971; 127:1189-93. http://dx.doi.org/10.1176/ajp.127.9.1189

2. Henning $\mathrm{P}$, Tomlinson L, Rigden SPA. Long term outcome of treatment of end stage renal failure Archives of Disease in Childhood 1988; 63:35-40. http://dx.doi.org/10.1136/adc.63.1.35

3. Trond H, Trine T, Trude R, Anne B. Kidney transplantation in childhood: mental health and quality of life of children and caregivers. Pediatric Nephrology 2011; 26:1881-92. http://dx.doi.org/10.1007/s00467-011-1887$\underline{9}$

4. Sabbet BF, Leventhal JM. Marital adjustment to chronic childhood illness: a critique of the literature. Paediatric 1984; 73:762-8.

5. Korrsch B, Fine R, Negrete VF. Experiences with children and their families during extended haemodialysis and kidney transplantation. Pediatric Clinics of North America 1971; 18:625-37.

6. Wolters W, Daniels-Wegdam T. Family reactions to the haemodialysis of a child. Acta Paedopsychiat(Basel) 1980;45:345-52.

7. Wass V, Barratt T, Howarth R, et al. Home haemodialysis in children. Lancet 1977; i: 242-6.

8. Morel P, Almond PS, Matas AJ, et al. Long term quality of life after kidney transplantation in childhood. Transplantation 1991; 52:47-53. http://dx.doi.org/10.1097/000078901991070 $\underline{00-00010}$

9. Kumar R, Eymann A, Ferraris J. Quality of life after kidney transplantation in children. Transplantation 1997; 64:540-1.
10. Karrfelt H, Berg U. Long term psychosocial outcome after renal transplantation during childhood. Paediatric Transplantation 2008; 12:557-562.

http://dx.doi.org/10.1111/j.13993046.2007.0 0859.x

11. Qvist E, Narhi V, Apajasalo M, et al. Psychosocial adjustment and quality of life after renal transplantation in early childhood Paediatric Transplantation 2004; 8:120-5.

12. Soliday E, Kool E, Lande MB. Psychosocial adjustment in children with kidney disease Journal of Pediatric Psychology 2000; 25:93-103.

http://dx.doi.org/10.1093/jpepsy/25.2.93

13. Karrfelt HM, Lindblad FI, Berg UB. Renal transplantation: long term adaptation and the children's own reflections. Paediatric Transplantation 2000; 7:69-75. http://dx.doi.org/10.1034/j.13993046.2003.0 $\underline{0018 . x}$

14. Falger J, Landol M, Latal B, et al. Outcome after renal transplantation Part 11: quality of life and psychosocial adjustment. Pediatric Nephrology 2008; 23:1347-54. http://dx.doi.org/10.1007/s00467-008-0798$\underline{\mathrm{x}}$

15. Reynold J, Garralda M, Goh D. Changes in psychosocial adjustment after renal transplantation. Archives of Disease in Childhood 1991; 66:508-13

http://dx.doi.org/10.1136/adc.66.4.508

16. Varni JW, Seid M, Rode CA. The PedsQL: Measurement model for the paediatric Quality of Life Inventory version 4.0. Medical Care 1999; 37:126-39 http://dx.doi.org/10.1097/000056501999020 $\underline{00-00003}$

17. Varni JW, Seid M, Kurtin PS. PedsQL 4.0: Reliability and validity of the Paediatric Quality of life inventory version 4.0 generic score scales in healthy and patient population. Medical Care 2001; 39:800-12. http://dx.doi.org/10.1097/000056502001080 $\underline{00-00006}$

18. Wallander JL, Varni JW. Effects of paediatric chronic physical disorders on child and family adjustment. Journal of 
Child Psychology and Psychiatry 1998; 39:29-46

http://dx.doi.org/10.1111/1469-7610.00302

19. Lavigne JV, Faier-Routman J. Psychological adjustment to paediatric physical disorders:

a meta-analytic review. Journal of Paediatric Psychology 1992; 17:133-57

http://dx.doi.org/10.1093/jpepsy/17.2.133

20. Garralda ME, JamesonRA, Reynolds JM. Psychiatric adjustment in children with chronic renal failure. Journal of Child Psychology and Psychiatry 1988; 29:79-90 http://dx.doi.org/10.1111/j.14697610.1988.t b00691.x

21. Reynold J, Garralda M, Jameson RA. How parents and families cope with chronic renal failure. Archives of Disease in Childhood 1988; 63:821-6

http://dx.doi.org/10.1136/adc.63.7.821

22. Goldstein SL, Graham N, Burwinkle T. Health related quality of life in paediatric patients with ESRD. Pediatric Nephrology 2006; 21 : 846-50.

http://dx.doi.org/10.1007/s00467-0060081-y

23. Anthony SJ, Hebert D. Child and parental perspectives of multidimensional quality of life outcomes after kidney transplantation. Paediatric Transplantation 2010; 14:24956.

http://dx.doi.org/10.1111/j.13993046.2009.0 1214.x

24. Neuhaus TJ, Wartmann M, Weber $M$. Psychosocial impact of living related kidney transplantation on donor and partners. Pediatric Nephrology 2005; 20:205-209 http://dx.doi.org/10.1007/s00467-004-1749$\underline{9}$

25. Sampson TF. The child in renal failure. Journal of the American Academy of Child and Adolescent Psychiatry 1975; 14:462-76. http://dx.doi.org/10.1016/S00027138(09)61 446-1 